\title{
Grid integration impacts on wind turbine design and development
}

\author{
Hansen, Anca Daniela; Cutululis, Nicolaos Antonio; Sørensen, Poul Ejnar; lov, F.
}

Published in:

IEEE Bucharest PowerTech, 2009

Link to article, DOI:

10.1109/PTC.2009.5282043

Publication date:

2009

Document Version

Publisher's PDF, also known as Version of record

Link back to DTU Orbit

Citation (APA):

Hansen, A. D., Cutululis, N. A., Sørensen, P. E., \& lov, F. (2009). Grid integration impacts on wind turbine design and development. In IEEE Bucharest PowerTech, 2009 (Vol. 1-5, pp. 632-638). IEEE Power and Energy Society. https://doi.org/10.1109/PTC.2009.5282043

\section{General rights}

Copyright and moral rights for the publications made accessible in the public portal are retained by the authors and/or other copyright owners and it is a condition of accessing publications that users recognise and abide by the legal requirements associated with these rights.

- Users may download and print one copy of any publication from the public portal for the purpose of private study or research.

- You may not further distribute the material or use it for any profit-making activity or commercial gain

- You may freely distribute the URL identifying the publication in the public portal 


\title{
Grid integration impacts on wind turbine design and development
}

\author{
A.D. Hansen, N. A. Cutululis, Member, IEEE, P. Sørensen, Senior Member, IEEE, and F. Iov, Senior \\ Member, IEEE
}

\begin{abstract}
This paper presents an overall perspective on contemporary issues like wind power plants and grid integration. The purpose is to present and discuss the impacts of emerging new grid connection requirements on modern wind turbines. The grid integration issue has caused several new challenges to the wind turbine design and development. The survival of different wind turbine concepts and controls is strongly conditioned by their ability to comply with stringent grid connection requirements, imposed by utility companies. Beside its impact on the mechanical design and control of wind turbines, the grid integration aspect has also an effect on wind turbines' role in the power system, on wind turbine technologies' survival on the market, as well as on the wind turbines' loads. Over the last years, it became obviously, that there it is an increasing need for design and research of wind turbines based on an integrated design and control approach.
\end{abstract}

Index Terms - control, grid integration, grid requirements, power system, wind power plants.

\section{INTRODUCTION}

$\mathrm{T}$ HROUGHOUT the world, there it is an increasing trend and demand of connecting large MW capacity wind farms to the transmission power system. The electrical power system thus becomes more vulnerable to and dependent on the wind energy production, and therefore there is an increased concern about the large wind turbines impact's on grid stability.

This fact has challenged different wind turbine manufactures and initiated important research activity directed towards connecting and optimized integration of large wind farms within the electrical power grid.

Fig. 1 sketches both an historic and a future perspective of the grid integration and wind turbines development. This figure provides an overall insight into this paper's approach, and therefore it is referred and used over the whole paper to explain different central issues. Notice that before millennium change, the grid integration and the design of wind turbines were more or less two independent issues.

The Danish Energy Agency is acknowledged for funding this work in contract number PSO-F\&U 2006-1-6319.

A.D. Hansen, N. A. Cutululis, Poul Sørensen are with Wind Energy Department, Risø National Laboratory for Sustainable Energy Technical University of Denmark - DTU, DK-4000 Roskilde, Denmark (email: anca@risoe.dtu.dk, niac@risoe.dtu.dk,posq@risoe.dtu.dk)

F. Iov is with the Institute for Energiteknik, Aalborg University, DK-9220 Aalborg East (email: fi@iet.auc.dk)

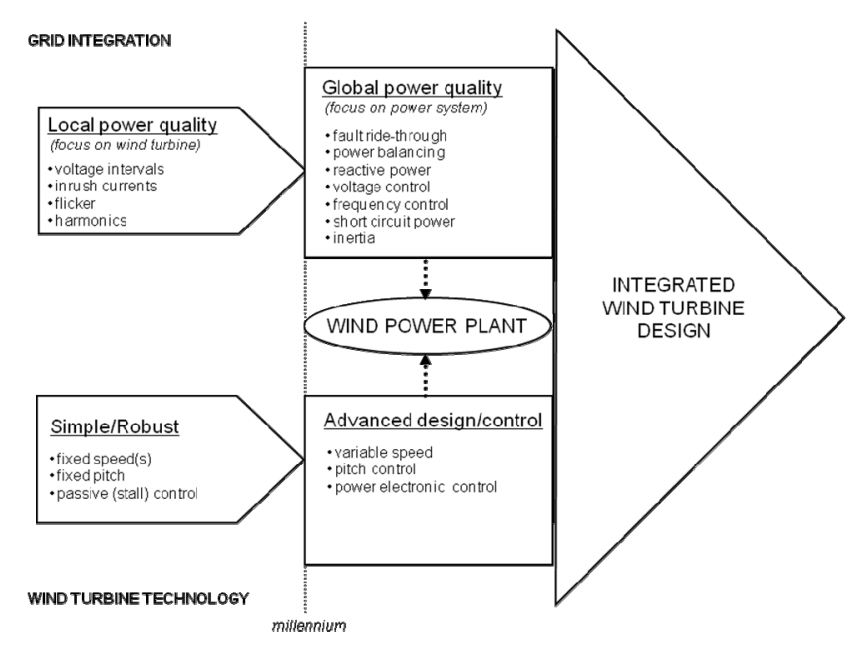

Fig. 1. Wind power plant and grid integration.

For example, in the 1980'ies, the wind turbines with a simple and robust design, typically fixed speed (with squirrel cage induction generator SCIG), fixed pitch and stall control predominated. They were connected directly to the low/medium voltage grid (i.e. distribution system) as simple passive components. At that time, the main power quality concern was to ensure that the voltage in the distribution grid was kept within an acceptable range - i.e. local power quality issue [1].

The high wind energy penetration into the power system over the years has influenced the focus on the power quality issues. In the last few years, the trend has moved from installations including few wind turbines connected to distribution system to large wind farms with capacity over hundreds of MW, connected directly to the transmission system. For example, in Denmark, two large offshore wind farms were connected directly to the transmission system in 2002 and 2003. One is the 160MW Horns Rev wind farm based on variable speed wind turbines with doubly-fed induction generators, while the other one is the $165 \mathrm{MW}$ Nysted wind farm based on fixed speed active stall wind turbines. Furthermore, two other wind farms of $215 \mathrm{MW}$ each, placed close to the previous mentioned, are planned to be operating already in 2009-2010. For such large wind farms the focus in the power quality is drawn toward large power system and wind power integration problem, where the power system control and stability issues are addressed - i.e. global power quality issue [1].

As shown in Fig.1, the wind turbine technology has been subjected to a continuous transformation. As well as becoming 
larger, wind turbine designs were progressing from fixedspeed, stall-controlled and with drive trains with gearboxes, to pitch controlled, variable speed and with or without gearboxes. The wind turbine design objectives have also changed over the years from being convention-driven to being optimised-driven within the operating regime and market environment. The present general availability of low-cost power electronics increasingly supports the trend toward variable speed turbines.

\section{GRID REQUIREMENTS}

The connection of large wind turbines to the grid has a large impact on grid stability. The increased penetration of wind energy into the power system over the last decade has therefore led to serious concern about its influence on the dynamic behaviour of the power system. It has resulted in the power system operators revising and increasing the grid connection requirements in several countries. An overview of the national grid requirements in countries as Denmark, Ireland, Germany, Great Britain, Spain, Italy, USA and Canada is also provided in [2].

As sketched in Fig.1, the main attention in the grid requirements is drawn to the fault ride-through and power control capabilities of large wind farms.

\section{A. Fault ride-through capability}

The fault ride-through requirement has been imposed in order to avoid significant loss of wind turbine production in the event of grid faults. Up to 7-8 years ago, wind turbines were only required to be disconnected from the grid when a grid fault was detected, in order thus to avoid large inrush currents when the voltage recovered. However, with the increased capacity of wind power in the power system over the years, such a disconnection of wind turbines could generate control problems of frequency and voltage in the system, and as worst case a system collapse.

The fault ride-through capability addresses primarily the design of the wind turbine controller in such a way that the wind turbine is able to remain grid-connected during grid faults. The fault ride-through demand is also a challenge on how to recover the voltage after a grid fault. This is especially the case of wind turbines with squirrel cage induction generator which, by being kept connected to the grid during grid faults may require large currents to energize their induction generators, when the voltage returns after a while. This can lead to possible violation of grid codes and security standards.

The fault ride-through capability depends on the particular wind turbine technology. The early generation of wind turbines would disconnect from the grid even during quite small disturbances as they did not have any fault ride-through capability, in accordance with the grid codes that were valid at the time of their installation. Modern wind turbines, e.g. those with doubly fed induction generator (DFIG) are able to stay connected during and after the fault, if they are equipped with a frequency converter protection system. Furthermore, they are able to support the power system and even improve the behaviour of local wind turbines with conventional technology, if they are equipped with appropriate control for grid support [3].

A summary of the fault ride-through requirement in different national grid codes is given in TABLE I. Notice that some national grid codes e.g. Denmark and Ireland have specific fault ride-through requirements for distribution networks as well as for transmission ones, while other national grid codes have focus only on the transmission level. The voltage profiles in these national requirements are given specifying the depth of the voltage drop and the clearance time as well. In some of the grid requirements, as in Denmark, Íreland and Germany, the definition of the voltage profile is clearly specified regarding the type of the fault, i.e. symmetric or asymmetric.

TABLE I

SUMMARY OF NATIONAL FAULT RIDE-THROUGH REQUIREMENTS - SOURCE [2].

\begin{tabular}{|l|c|c|c|c|c|c|}
\hline \multirow{2}{*}{ Country } & \multirow{2}{*}{$\begin{array}{c}\text { Voltage } \\
\text { Level }\end{array}$} & $\begin{array}{c}\text { Fault } \\
\text { duration }\end{array}$ & $\begin{array}{c}\text { Voltage } \\
\text { drop level }\end{array}$ & $\begin{array}{c}\text { Recovery } \\
\text { time }\end{array}$ & $\begin{array}{c}\text { Voltage } \\
\text { profile }\end{array}$ & $\begin{array}{c}\text { Reactive } \\
\text { current } \\
\text { injection }\end{array}$ \\
\hline \multirow{2}{*}{ Denmark } & DS & $100 \mathrm{msec}$ & $25 \% \mathrm{U}_{\mathrm{r}}$ & $1 \mathrm{sec}$ & $2,3-\mathrm{ph}$ & no \\
\cline { 3 - 7 } & $\mathrm{TS}$ & $100 \mathrm{msec}$ & $25 \% \mathrm{U}_{\mathrm{r}}$ & $1 \mathrm{sec}$ & $1,2,3-\mathrm{ph}$ & no \\
\hline Ireland & $\mathrm{DS} / \mathrm{TS}$ & $625 \mathrm{msec}$ & $15 \% \mathrm{U}_{\mathrm{r}}$ & $3 \mathrm{sec}$ & $1,2,3-\mathrm{ph}$ & no \\
\hline Germany & $\mathrm{TS}$ & $150 \mathrm{msec}$ & $0 \% \mathrm{U}_{\mathrm{r}}$ & $1.5 \mathrm{sec}$ & generic & $\begin{array}{c}\text { Up to } \\
100 \%\end{array}$ \\
\hline Great \\
Britain
\end{tabular}

Notice that there is a significant span in the fault ridethrough requirements in different countries. For example, the fault duration varies from $100 \mathrm{msec}$ (in Denmark) to $625 \mathrm{msec}$ (in Ireland, USA and Canada), while the voltage drop level down varies between $25 \%$ to even $0 \%$ of the nominal value. The Ireland's code is very demanding regarding the fault duration, while Denmark has the lowest fault duration with only $100 \mathrm{msec}$. However, Denmark's code requires the wind turbine to remain connected to the grid during successive faults. The German grid code requires the wind turbines to remain connected to the grid during voltage sags down to $0 \%$ from the rated voltage in the PCC for a duration of $150 \mathrm{msec}$. Moreover, a reactive current injection up to $100 \%$ during fault is required, this requirement being also present in the Spanish grid code.

\section{B. Power control capability}

Besides fault ride-through capability, the Danish grid requirements address today also the power control ability of large wind farms. The power control ability means mainly that the wind turbines have to share, for shorter or longer periods, some of the duties carried out traditionally by conventional power plants, such as regulating active and reactive power and performing frequency and voltage control on the grid.

The power control capabilities requirements correspond basically to the wind farm controllers implemented for the two large Danish wind farms, namely 160MW Horns Rev wind 
farm [4] and 165MW Nysted wind farm. These large wind farms are equipped with capable power control features with remote access. Even though they are consisting of different wind turbine concepts, having thus different dynamic response to the control request, their power control behaviour is quite similar.

As sketched in Fig.1, the power control requirements regard different power system control and stability aspects:

- active power/frequency control ability with focus on:

- primary control - is a fast, automatic global adjustment of power to frequency.

- secondary control - is a slower, automatic or manual regional regulation of the power to the power reference imposed by the system operator at any time.

- reactive power/voltage control ability with focus on voltage regulation and reactive power capability.

- dynamic stability with focus on the ability of wind farms to withstand some specific grid faults without being disconnected.

Modern wind farms have to provide advanced grid support [4], [5], such as the following different control functions, illustrated in Fig.2:

- Balance control - whereby the wind farm production can be adjusted downwards or upwards, in steps at constant levels.

- Delta control - whereby the wind farm is ordered to operate with a certain constant reserve capacity in relation to its momentary possible power production capacity.

- Power gradient limiter - which sets how fast the wind farm power production can be adjusted upwards and downwards.

- Automatic frequency control - whereby the wind farm must be able to produce more or less active power in order to compensate for a possible deviant behaviour in the frequency measured in the wind farm point of common coupling (PCC).

- Reactive power control - whereby the wind farm is required to produce or absorb a constant specific amount of reactive power.

- Automatic voltage control - whereby the wind farm automatically produces or consumes an amount of reactive power in order to control the voltage in the point of common coupling (PCC) of the wind farm.

The power system operators are not only requiring power plant characteristics for the wind turbines, but also development of suitable dynamic models to assess the wind generation impact on system stability. Such models play an important role in the design of national grid codes. Various wind turbine manufactures have also been challenged to initiate research activities directed towards connection and optimised integration of large wind farms within the electrical power grid. Risø-DTU National Laboratory has developed a dynamic simulation model for wind farms [1], [3], [6], including both wind farm controllers, individual wind turbine controllers and the dynamics of the wind turbines themselves.
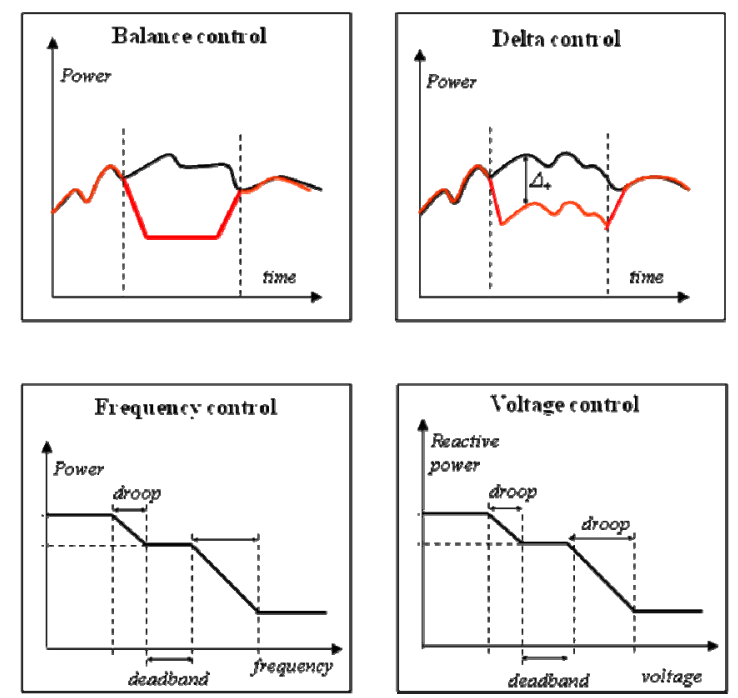

Fig. 2. Different control functions in modern wind farms.

Fig.3 illustrates the general structure of such wind farm model, which is similar to what is actually implemented in the Danish Horn Rev and Nysted farms. All the demands illustrated in Fig.2, can be imposed by the power system operator to the wind farm controller. The wind farm controller controls the power production from the whole wind farm by issuing instructions (power references) to each individual wind turbine, each of which having its own controller. These instructions are prepared based on the power system demands, measurements in PCC and on the received information from the wind turbines about the maximum amount of available power.

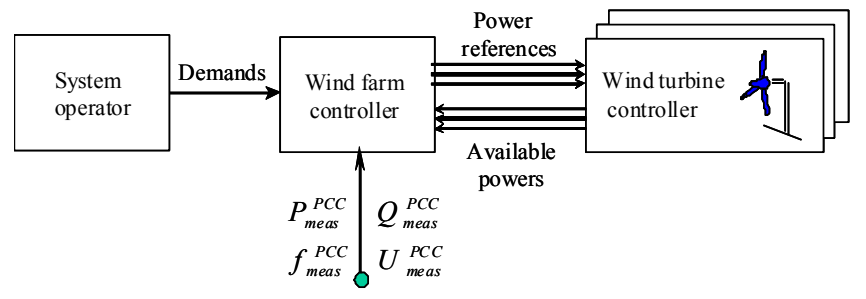

Fig. 3. The general structure of a wind farm control system.

In the following, different aspects of the grid integration impacts on the wind turbine design and development are briefly discussed.

\section{WIND POWER PLANT STATUS}

Basically, the grid codes require wind turbines to have an operational behaviour more similar to that of conventional generation capacity and more responsibility in network operation. The status of wind turbines is thus changing from being simple energy sources to having power plant status. This means that sooner or later, they will have to share some of the duties carried out today by the conventional power plants, namely behave as active controllable components [1] in the power system, i.e. regulating active and reactive power and performing frequency and voltage control on the grid - see Fig.2. 


\section{WIND TURBINE CONCEPTS' MARKET PENETRATION}

Today, the wind turbines on the market have a variety of innovative concepts, with proven technology for both generators and power electronics [7]. The continuously increased and concentrated electrical penetration of large wind turbines into electrical power systems inspires the designers to develop both custom generators and power electronics, and to implement modern control system strategies [8].

The survival of different wind turbine technologies is strongly conditioned today by their ability to support the grid, to handle faults on the grid and to comply with the stringent requirements of power system operators.

The main role in meeting the technical demands of the grid operators is played today by the power electronics within the wind turbines and wind farms. The presence of power electronics leads to increased interest in variable speed concepts, i.e. variable speed wind turbine concept with partialscale power converter (DFIG) and the variable speed concept with full-scale power converter. Today, these variable speed wind turbine concepts already have a substantial and increasing share of the wind power market [9]. Variable speed operation is attractive for wind turbines within wind farms for a number of reasons, including reduced mechanical stress, increased power capture, reduced acoustical noise and, not least, controllability, which is a prime concern for the grid integration of large wind farms. In the future, it seems that they still may dominate and be very promising wind technologies for large wind farms.

\section{WIND TURBINE LOADS AND CERTIFICATION STANDARDS}

A typical design basis analysis of wind turbine loads and lifetime includes today the distribution of fatigue loads and extreme loads for normal, start and shut-down operations. Besides these aspects, it could also be relevant to know how different the wind turbine loads caused by grid faults and by the fulfilment of the grid requirements are, compared to the wind turbines loads during standard shut-down operations.

The fulfillment of the grid requirements poses challenges for the design of both the electrical system and the mechanical structure of wind turbines. From an electrical point of view, these challenges imply development of advanced controllers of wind turbines adapted to fulfil the grid requirements. However, the design of such controllers, suitable to ensure the fulfillment of the grid requirements, requires also a better understanding of their influence on the wind turbines structural loads.

This issue has not been sufficiently investigated in the relevant literature. Up to now, no clarified knowledge and investigations, on how the fulfillment of the new grid requirements affects the wind turbine structural loads, exist. Some investigations have been initiated at Risø-DTU National Laboratory and described in [10]. They are very important in order to evaluate and define possible new directions in the certification process of future power plant wind turbines, namely wind turbines which participate actively in the stabilization of power systems.

Grid faults are basically experienced by the wind turbine as changes in the voltage at the generator terminal. This causes typically transients in the generator electromagnetic torque, which result in significant stress of the wind turbine mechanical system and may also have a detrimental effect on the drive train components, such as the gearbox. Practice experience indicates that grid faults have a very direct impact on drive train loads, but also impact on other loads could have high relevance. A focus directed to loads caused during grid fault operation can thus provide a more complete understanding of the loads distribution during the whole wind turbine lifetime.

Nowadays, analysis of wind turbine loads caused by grid faults is even more important especially in terms of lifetime of the wind turbines with regard to the fulfilment of the fault ride-through requirements. The continuous increase of wind turbine size and of wind energy penetration level into power networks, makes the presence of an advanced controller to become crucial in order to ensure fulfilment of the grid requirements and thus a better power system operation. Significant research has been and is currently done to develop advanced fault ride-through controllers. Nevertheless, the design of such advanced control schemes, that enable wind turbines to fulfil the grid requirements, requires a better understanding on the effects on the wind turbines loads, as no clarified knowledge and investigations on how the fulfilment of the new wind turbine grid codes affects the structural loads.

One should have in mind that the fast development of the wind energy industry implies a continuous revision not only of the grid connection requirements, but also of the certification standards. These standards have to specify the essential wind turbine design requirements to ensure the engineering integrity of wind turbines. They are at the moment not updated according to the progress of technology, knowledge and new grid connection requirements. IEC 61400-1 certification standard, (paragraph 7.4) [11], presents for example a list with different design situations and load cases (i.e. faults during normal or parking operation). Loss of the electrical power network, voltage/frequency ranges, voltage unbalance are specified, but not really dealt with in certification. IEC 614001 certification standard stipulates the wind turbines to be designed to withstand electrical faults and any other type of abnormal operating conditions that may occur in the grid, but it does not state requirements in terms of specific faults to be considered, leaving this task to the designer and the certifier of the wind turbine.

\section{CASE STUDY: GRID FAULTS IMPACT ON LOADS}

In order to investigate the impact of grid faults on wind turbine loads, a simplified simulation scenario of a short circuit in a reduced wind power installation is performed.

In this respect, two complimentary simulation tools, namely Power Factory from DIgSILENT and HAWC2 (Horizontal Axis Wind turbine Code) are considered in this work. DIgSILENT is a dedicated electrical power system simulation tool used to model the dynamic behaviour of power systems and for assessment of power quality and analysis of wind turbines grid integration. HAWC2 is an aeroelastic simulation code, developed at 
Risø-DTU National Laboratory, used to model very detailed the aeroelastic and mechanical aspects in a wind turbine. By using these two simulation tools with complimentary abilities in the attempt to put them to work together to the extent that is possible, it is achieved a complete combination of structural dynamics and generator dynamics.

In this case study, DIgSILENT tool is used to simulate the grid fault and the electrical interaction between the wind turbine, while HAWC2 is used to simulate and analyze the structural loads of the wind turbine during the grid fault.

A $2 \mathrm{MW}$ active stall wind turbine is considered for the present study. It is equipped with a squirrel-cage induction generator, which is connected to a typical-medium voltage (MV) distribution network through a step-up transformer, as illustrated in Fig.4.

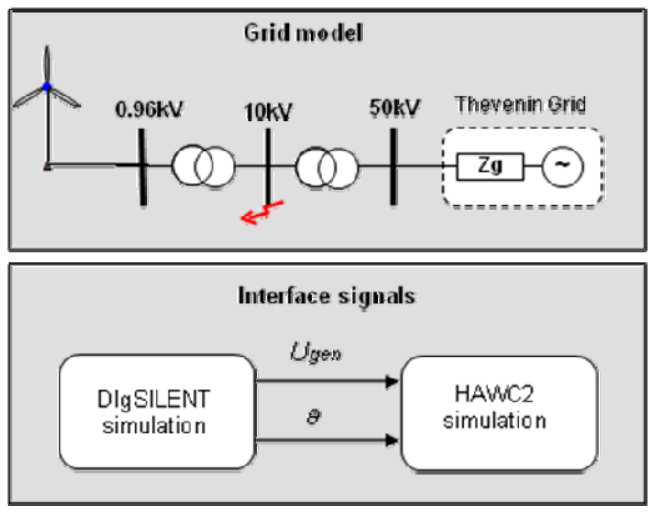

Fig. 4. Simulation setup and interface signals.

The implemented wind turbine model in DIgSILENT contains detailed models only for the electrical components of the wind turbine, while the wind turbine model in HAWC2 contains detailed models only for the aeroelastic and mechanical aspects in a wind turbine.

The wind turbine model used in DIgSILENT is the benchmark model presented in [10]. It is assumed that the aerodynamic torque is kept constant through and after the short circuit. The wind turbine model in DIgSILENT also contains a fault ride-though controller, which enables the quick reduction of the aerodynamic power production of the wind turbine during grid faults.

As illustrated in Fig.4., the grid model is represented by a Thevenin equivalent, consisting of a constant magnitude/frequency voltage source and a serial impedance. A 3 phase short circuit on $10 \mathrm{kV}$ busbar, with duration $100 \mathrm{~ms}$, is simulated in DIgSILENT by using the RMS (electromechanical transient models) simulation feature for longer-term dynamics.

In order to assess the maximum wind turbine structural stresses developed during grid faults, the worst scenario is simulated, i.e. wind turbine operates at rated power, minimum fault impedance and fault closest to the wind turbine.

As shown in Fig.4, the generator voltage signal and the pitch angle simulated in DIgSILENT are used as interface signals, i.e. as inputs in the wind turbine HAWC2 model.
In order to quantify how the grid faults and grid codes fulfillment do affect the wind turbine loads and thus wind turbines lifetime, a statistical analysis of the fatigue and ultimate loads for the wind turbine has to be performed. In such analysis, the considered load cases should be according to the design load cases presented in the IEC standard [11]. This standard includes a comprehensive list of design situations for fatigue and ultimate load analysis.

The fatigue load analysis is presented in the following. It is based on load cases for normal operation, which according to [11], include 2 situations to be considered:

- Power production (DLC1.2)

The IEC standard specifies here that, for each wind speed between cut-in and cut-out, six 10-minutes simulations with different turbulence seed have to be performed.

- Power production with fault occurrence (DLC2.4).

The IEC standard specifies here that, for each wind speed between cut-in and cut-out, twelve 10-minutes simulations with different turbulence seed have to be performed.

In the present study, for each load situation, 10-minutes simulations are performed from $6 \mathrm{~m} / \mathrm{s}$ to $24 \mathrm{~m} / \mathrm{s}$ with a $2 \mathrm{~m} / \mathrm{s}$ step. A 20 years life-time is assumed and the probability of each wind speed is calculated based on the Weibull distribution. The turbulence intensity is for a Class A turbine (high turbulence). For the power production with fault occurrence situation, it is assumed that a number of 500 fault occurrences during 20 years is realistic.

The present fatigue analysis for the load situation with fault occurrence considers the following two cases:

Case1: Emergency stop - when the wind turbine is immediately disconnected from the grid when a grid fault occurs - by ramping the pitch angle to minus 90degrees with a slope of $8 \mathrm{deg} / \mathrm{sec}$.

Case2: Fault ride-through -when the wind turbine is equipped with a fault ride-through controller and it is therefore able to remain connected to the grid even during grid faults. The idea of such controller is that, when a grid fault is detected, the production power is reduced, i.e. to $20 \%$ of the rated power. After the fault is cleared and the voltage has recovered during at least 5 seconds, the power reference is again set to its rated value.

The interface signals between DIgSILENT and HAWC2 for these two cases are illustrated in Fig.5.
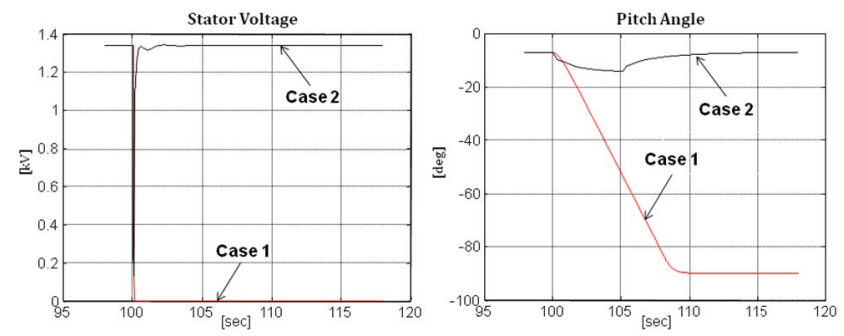

Fig. 5. Interface signals (generator voltage and pitch angle) during grid faults for Case 1 and Case 2 
The ratio Case2/Case1 of the equivalent loads for the blade, tower and shaft of the turbine are shown in TABLE II.

Notice that for the considered case study and for the assumed fault occurrences of 500 in 20 years, there is no significant difference in the effect of emergency stop (Case 1) and fault ride-through operation (Case 2) on the fatigue loads for any of the sensors (blade flap moment, blade edge moment, tower top tilt moment, tower top yaw moment, tower bottom tilt moment, tower bottom side moment, shaft bending moment). As expected, the normal operation is dominant for fatigue loads. The fatigue load analysis shows thus that for the considered case study, the fulfillment of the grid requirements, i.e. fault ride-through requirement, does not influence the lifetime of the wind turbine more that the traditional emergency stop.

TABLE II

Equivalent loads for power production with fault occurrence Case2/Case 1

\begin{tabular}{|l|l|}
\hline Load sensor (1Hz eq. load) & Case2/Case1 \\
\hline Blade flap moment & 0.999999 \\
\hline Blade edge moment & 0.999949 \\
\hline Tower top tilt moment & 0.999996 \\
\hline Tower top yaw moment & 1.000045 \\
\hline Tower bottom tilt moment & 0.996970 \\
\hline Tower bottom side moment & 1 \\
\hline Shaft bending moment & 0.999963 \\
\hline
\end{tabular}

The fatigue load analysis has been presented in this first place. A case study considering a fault occurrence during an extreme operating gust (EOG) is likely to show an increased loading and therefore an ultimate load analysis could also be relevant to perform. Such analysis will therefore be addressed in a coming paper, as a natural next step of the investigation. The first impression is, however, that a more probable effect of the fault ride-through requirement on the wind turbine loads can be expected from such ultimate load analysis.

\section{INTEGRATED WIND TURBINE DESIGN}

At the moment, the design and the research of wind turbines take place in specific dedicated simulation tools, which are specialised either in the mechanical design area or in the electrical design area regarding grid integration issues of wind turbines. Grid faults are for example typically simulated in dedicated power system simulation tools, based on detailed models for the electrical components of the wind turbine and of the grid, while structural loads of wind turbines are typically assessed in advanced aeroelastic computer codes, which take the flexibility of the tower, blades and other components of the wind turbines into account.

The expertise in these wind turbine design areas is thus built-up independently, with very specific focus and without any influence from one design area to another. In spite of this fact, practical experience shows that there is a considerable interplay between these design areas, which is necessary to take into account. It seems likely that the increased requirements regarding wind turbines response during grid faults may have significant influence on the structural loads of the wind turbine. In order to achieve a thorough insight and understanding on how grid fault affects the structure of the wind turbine itself, it is therefore necessary to use and combine, in an integrated way, knowledge from simulation tools, which have their expertise in such different specialised design areas for wind turbines, as illustrated in Fig.6.
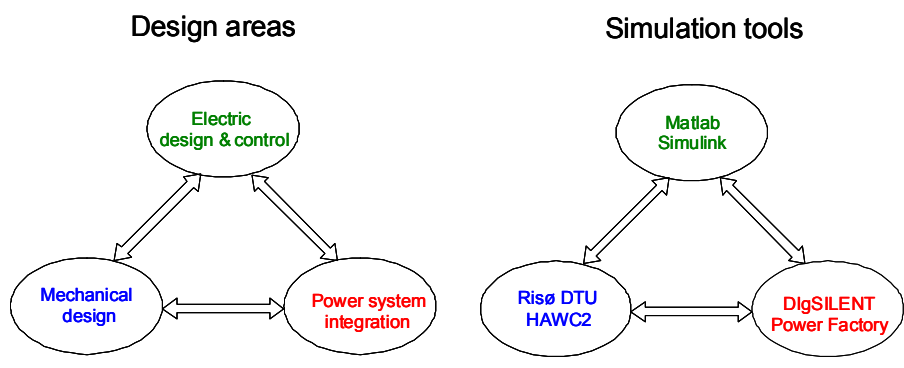

Fig. 6. Integrated wind turbine design.

The knowledge from different domains, i.e. electric design and control, mechanical design and power system integration, has to be accessed and combined in an integrated and dynamic way. These ideas are the background of two on-going research projects carried out at Risø-DTU National Laboratory, where different procedures for an integrated insight into both the structural as well as the electrical wind turbine dynamic are investigated [12]. In order to achieve such thorough insight the strengths of different complimentary simulation tools are combined, i.e. DIgSILENT, HAWC2 and Matlab - as illustrated in Fig.4. DIgSILENT has skills on detailed electrical modelling of the interaction between wind turbine and the electrical grid during grid fault, HAWC2 has skills on detailed aeroelastic and mechanical loads modelling of wind turbines, while Matlab has skills in design of control, respectively.

The combination of such complimentary tools can therefore provide a detailed insight into the structural as well as the electrical design and control and this is very important in order to quantify the loads' impact on the wind turbines' lifetime, during and after grid faults. Once the whole complex model is established, it is possible to investigate sequentially the whole integrated wind turbine design. The goal with such investigation is to get an overview of the whole system and eventually define new improvements for both the electrical and mechanical side of the wind turbine.

\section{CONCLUSION}

The development of wind power the last 30 years in Denmark has caused a steadily increased concern on the influence that wind power has on the power system.

The increased penetration of wind power in the power system, challenges continuously both the transmission system operators and the wind turbine manufactures all over the world. In a general perspective, this paper presents all these challenges involved and some possible solutions, with focus on power system and wind turbine technology development. 


\section{ACKNOWLEDGEMENT}

This paper describes the ongoing results of the project titled "Grid fault and design-basis for wind turbines". The Danish Energy Agency is acknowledged for funding this work in contract number PSO-F\&U 2006-1-6319. The work is carried out by the Wind Energy Department at Risø-DTU National Laboratory in cooperation with Aalborg University.

\section{REFERENCES}

[1] P. E. Sørensen, N. A. Cutululis, T. Lund, A. D. Hansen, T. Sørensen, J. Hjerrild, M. H. Donovan, L. Christensen, and H. K. Nielsen, "Power Quality Issues on Wind Power Installations in Denmark," part of: Power Engineering Society General Meeting, 2007. IEEE (ISBN: 1-4244-1298-6) (DOI: 10.1109/PES.2007.385924), pp. 2820-2826, 2007.

[2] F. Iov, A. D. Hansen, P. Sørensen, and N. A. Cutululis , "Mapping of grid faults and grid codes," Risø report, Risø-R1617(EN), 2007.

[3] A. D. Hansen, G. Michalke, P. Sørensen, T. Lund, and F. Iov, "Co-ordinated voltage control of DFIG wind turbines in uninterrupted operation during grid faults," Wind Energy, Vol. 10, No.1, pp.51-68, 2007.

[4] J. R. Kristoffersen, and P. Christiansen, "Horns rev offshore windfarm: its main controller and remote control system," Wind Engineering, Vol. 27, No. 5, pp. 351-360, 2003.

[5] EnergiNet, Transmission System Operator of Denmark for Natural Gas and Electricity (2004), "Wind turbines connected to grids with voltages above $100 \mathrm{kV}$ - Technical regulations for the properties and the control of wind turbines," Technical Regulations TF 3.2.5, [Online] Available: http:/www.energinet.dk.

[6] A.D. Hansen, P. Sørensen, F. Iov, and F. Blaabjerg, "Grid support of a wind farm with active stall wind turbines and $\mathrm{AC}$ grid connection," Wind Energy, vol. 6, pp. 341-359, 2006.

[7] F. Blaabjerg, and Z. Chen, "Power electronics as an enabling technology for renewable energy integration," $J P E$, vol.3, No.2, pp. 81-89, 2003.

[8] F. Iov, M. Ciobotaru, N. A. Cutululis, and F. Blaabjerg, "Power electronics: Key-Enabling Technology for grid integration of wind power," ISEEE, pp. 16, 2008.

[9] A. D. Hansen, and L. H. Hansen, "Market penetration of different wind turbine concepts over the years," EWEC, Milano, 2007.

[10] P. Sørensen, A.D. Hansen, P. Christensen, M. Meritz, B. Bak.Jensen, and H. Nielsen, "Simulation and verification of transient events in large wind power installations", Risø-R1331(EN), Okt. 2003.

[11] International electrotechnical commission (IEC) report 88/228/FDIS (2005), "IEC 61400-1 Ed.3: Wind turbine - Part 1: Design requirements".

[12] A. D. Hansen, N. Cutululis, P. Sørensen, F. Iov, and T. J. Larsen, "Grid faults' impact on wind turbine structural loads," NWPC, 2007.

\section{BIOGRAPHIES}

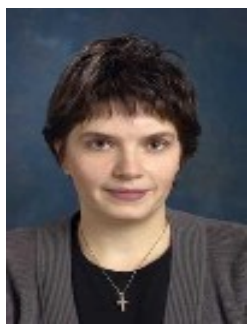

Anca D. Hansen received her Ph.D. in modelling and control engineering from Denmark Technical University in 1997. Since 1998 she has been employed at Risø-DTU National Laboratory in the Wind Energy Department - first as Post Doc., scientist and afterwards as senior scientist. Her working field and research interests are on the topics of dynamic modelling and control of wind turbines, as well as dynamic modelling and control of wind farms and on wind farm grid interaction. She is author or co-author of more than $80 \mathrm{journal} /$ conference papers, several research reports in her research fields, as well as a book contribution on wind power in power systems.

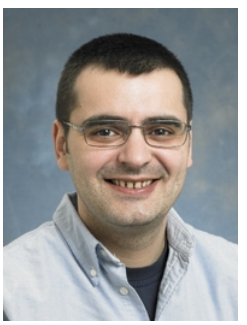

Nicolaos A. Cutululis (M'06) received the M.Sc. and $\mathrm{Ph} . \mathrm{D}$. degrees in electrical engineering and automatic control from the University of Galati, Romania, in 1998 and 2005, respectively. Since February 2005, he has been employed at Risø DTU, Denmark, presently as a Scientist. His main technical interest is integration of wind power into power systems, involving a variety of technical disciplines including integrated design, dynamic modeling and control of wind turbines and farms and wind fluctuation statistics. He is author or co-author of more than 50 journal/conference papers and several research reports, as well as a book on wind turbine control.

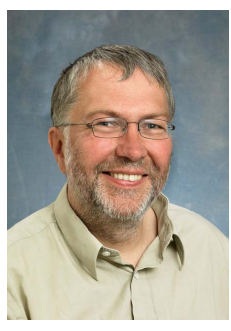

P. Sørensen (M'04, SM'07) was born in 1958. He received M.Sc. in electrical engineering from the Technical University of Denmark in 1987. Since 1987 he has been employed in the Wind Energy Division of Risø National Laboratory for Sustainable Energy, which is now a part of the Technical University of Denmark. His present position is Senior Scientist. His main technical interest is integration of wind power into power systems, involving a variety of technical disciplines including power system control and stability, dynamic modeling and control of wind turbines and wind farms, and wind power variability. He has been a member of the technical committees for the two editions of IEC 61400-21 on measurement and assessment of power quality of gird connected wind turbines. He is an editor on the Wiley journal Wind Energy.

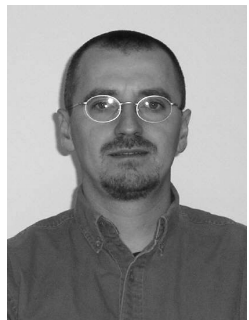

Florin Iov (IEEE SM '98, M '04, SM '06, Cigre SC C6 Expert, Reuters Insight Expert) was born on 26 August 1968 in Galati, Romania. He received the Dipl. Eng. degree in electrical engineering from University, Romania, in 1993 and a PhD degree from Galati University, Romania in 2003 with a special focus in the modeling, simulation and control of large wind turbines. He was staff member at Galati University, Romania from 1993 to 2001. Since 2001 he is with Institute of Energy Technology, Aalborg University, Denmark where he currently is associate professor. During the last years he was involved mainly in research projects regarding the wind turbine systems financed by the Danish authorities as well as by the industrial partners. His fields of interest are electrical machines, power converters including their control for grid integration of renewable energy sources, modeling and control of large wind turbines/farms and their grid integration. $\mathrm{He}$ is author or co-author of more than 80 journal/conference papers and several research reports in his research fields. 